\title{
Visualising maritime vessel open data for better situational awareness in ice conditions
}

\author{
Jari Jussila ${ }^{\dagger}$ \\ Häme University of Applied \\ Sciences \\ Finland \\ jari.jussila@hamk.fi \\ Markus Makkonen \\ University of Jyväskylä \\ Jyväskylä \\ Finland \\ markus.v.makkonen@jyu.fi
}

\author{
Timo Lehtonen \\ Solita Plc \\ Tampere \\ Finland \\ timo.lehtonen@solita.fi \\ Lauri Frank \\ University of Jyväskylä \\ Jyväskylä \\ Finland \\ lauri.frank@jyu.fi
}

\author{
Jari Laitinen \\ Solita Plc \\ Tampere \\ Finland \\ jari.laitinen@solita.fi
}

\begin{abstract}
Situational awareness of maritime vessels in ice conditions is important for the operation of supply chains. In the artic sea areas, the ice conditions pose a major challenge for maritime vessels getting stuck in the ice and being significantly delayed in arrival to harbor. Data science and open data provide new opportunities to overcome these challenges. This paper introduces available open data sources and data visualizations that can be used to develop applications, for example, for detecting maritime vessel collision, predicting estimated time of arrival to harbor, as well as maritime vessel route optimization in ice conditions. The paper begins by introducing available open data sources and existing computational studies on maritime vessels in ice conditions, then presents the developed data science solution and visualizations of the open data along with the open source software code, and finally concludes with a discussion on the potential application areas and opportunities for further research.
\end{abstract}

\section{CCS CONCEPTS}

- Computing methodologies $\rightarrow$ Machine learning; Machine learning approaches; - Information systems $\rightarrow$ Information systems applications $\rightarrow$ Decision support systems $\rightarrow$ Data analytics

\section{KEYWORDS}

Data science, open data, open source, AIS data, maritime vessel, ice conditions, situational awareness

Permission to make digital or hard copies of part or all of this work for personal or classroom use is granted without fee provided that copies are not made or distributed for profit or commercial advantage and that copies bear this notice and the full citation on the first page. Copyrights for third-party components of this work must be honored. For all other uses, contact the Owner/Author.

Mindtrek 2018, October 10-11, 2018, Tampere, Finland

C 2018 Copyright is held by the owner/author(s).

ACM ISBN 978-1-4503-6589-5/18/10. https://doi.org/10.1145/3275116.3275124

\section{Introduction}

Maritime 'digital footprints' remain underexplored in the existing literature despite the crucial importance of freight transport for global trade, for instance, it has been estimated that $90 \%$ of global trade volumes travel via maritime transport $[6,36]$. Situational awareness of maritime vessels in ice conditions is one important phenomenon for the operation of global supply chains. In the artic sea areas, the ice conditions pose a major challenge for maritime vessels getting stuck in the ice and being significantly delayed in arrival to harbor. Late arrival to harbor typically increases the cost of logistics and causes disturbances in the supply chain. Identifying such threats at an early stage would enable companies to react and possibly mitigate business risks $[12,13]$. Furthermore, as the analysis of navigational accidents in Northern Baltic Sea has uncovered, ship-to-ship collisions typically occur in sea ice conditions with a recognizable pattern that the vessels are heading to the same direction and the impacted vessel has typically stopped or is proceeding at low speed before collision [7]. Although competing solutions to using Automatic Identification System (AIS) data to prevent ship collisions may exist, these have not proven successful as ship-to-ship collisions remain the most frequent category of navigational accidents, e.g. 21 ship-to-ship collisions occurring during 2007-2013 in Northern Baltic Sea [7].

The importance of situational awareness of maritime vessels in ice conditions is increasing also due to the foreseen opening of the Northeast and Northwest transport corridors between the Eastern and Western parts of the world [35]. The problem of navigating in the artic sea areas and in ice conditions has been recognized in prior literature. Kvamstad et al. [19] call for improved access to high quality maritime data and also highlight the need to develop maritime communication infrastructure with at least the same quality, in terms of availability and integrity, as in other more centralized areas. In order to simulate, for instance, sea ice circulation and thickness over time, several sea ice models have 
been proposed [1, 2, 9, 11]. By making use of these sea ice models and AIS data, several systems have been proposed for the route optimization of maritime vessels in ice-covered waters [e.g. $8,17,31]$. However, in business operations, there is a need for more real-time approaches where, for example, the estimated time of arrival of maritime vessels in harbor would be made continuously available online and would immediately react to potential changes in the observed parameters. Furthermore, in order to avoid the collisions of ships, real-time or near real-time exchange of information is needed. According to ship escort and convoy operation statistics presented by Goerlandt et al. [7], the distance of vessels in a convoy is typically approximately 0.55 0.75 nautical mile (one nautical mile is equal to 1,852 metres). Therefore, a maritime vessel on a collision course in ice conditions has approximately only three to four minutes time to react to the abnormal speed changes of the vessel in front in order to avoid a collision, which could be predicted with open data and signaled as an alarm to halt the vessel - i.e., a 'collision radar'. Such a decision support would be welcome as a majority (from $80 \%$ to $85 \%$ ) of all recorded maritime accidents have been generally attributed to or associated with human error [10].

In this study, data science and open data are proposed as a solution that can respond to the outlined challenges and business needs. We recognize that data processing is the most important phase of the whole process as the success of the analysis strongly depends on it and may consume up to $90 \%$ of the time and resources [37]. Descriptive and diagnostic analytics [25, 34] are key tools for acquiring insight of any dataset. In addition, it is recognized that in data science, especially 'big data' research, the full documentation of the methods and the replicability of the results is a critical issue and often remains unaddressed in research $[3,4]$. Therefore, this study takes extra care to introduce the open data sources and to provide full documentation of the method as well as the open source software code of the developed data processing, analysis, and visualizations approaches introduced in the study.

The paper begins by introducing the available open data sources and existing computational studies on maritime vessels in ice conditions, then presents the developed data science solution and visualizations of the open data, and finally concludes with a discussion on the potential application areas and opportunities for further research.

\section{Open data sources for maritime vessels situational awareness}

The most important open information system for maritime vessels is the Automatic Identification System (AIS), which has been compulsory for most commercial ships, e.g., tankers as well as cargo and passenger vessels since 2002 [22, 29]. AIS was developed primarily as a tool for maritime safety in order to avoid vessel collisions [32]. AIS messages are autonomously and continuously broadcasted with a reporting frequency directly proportional to the speed of the vessel $[29,32]$. There are various types of AIS messages that can be classified as static and dynamic information [29]. Static information includes, e.g., name, type, and size of the vessel, whereas dynamic information includes, e.g., its position in geodetic coordinates, speed, course, heading, destination, and estimated time of arrival. An example of static AIS information is illustrated in Table 1, whereas an example of dynamic AIS information is illustrated in Table 2.

Table 1: Example of static vessel metadata information.

\begin{tabular}{|c|c|c|c|c|c|c|c|}
\hline $\begin{array}{l}\text { Time } \\
\text { stam } \\
\text { p }\end{array}$ & name & $\begin{array}{l}\text { ship } \\
\text { type }\end{array}$ & $\begin{array}{l}\text { call } \\
\text { sign }\end{array}$ & imo & $\underset{\mathrm{i}}{\mathrm{mms}}$ & des & eta \\
\hline $\begin{array}{l}2018 \\
-03- \\
20 \\
11: 3 \\
6\end{array}$ & $\begin{array}{c}\text { BAL- } \\
\text { TIC } \\
\text { MAD } \\
- \\
\text { ONN } \\
\text { A }\end{array}$ & 70 & OJRV & $\begin{array}{l}9100 \\
138\end{array}$ & $\begin{array}{l}2306 \\
6600 \\
0\end{array}$ & $\begin{array}{l}\text { TURK } \\
\text { U VIA } \\
\text { KAL- } \\
\text { MARS }\end{array}$ & $\begin{array}{l}238 \\
400\end{array}$ \\
\hline $\begin{array}{l}2018 \\
-03- \\
20 \\
11: 3 \\
6\end{array}$ & $\begin{array}{l}\text { TRI- } \\
\text { TON }\end{array}$ & 52 & OJLX & $\begin{array}{l}9426 \\
958\end{array}$ & $\begin{array}{l}2309 \\
8938 \\
0\end{array}$ & $\begin{array}{l}\text { MUU- } \\
\text { GA }\end{array}$ & $\begin{array}{l}158 \\
976\end{array}$ \\
\hline $\begin{array}{l}2018 \\
-03- \\
20 \\
11: 3 \\
6\end{array}$ & $\begin{array}{l}\text { KEM } \\
\text { I } 1\end{array}$ & 52 & OIOM & $\begin{array}{l}7636 \\
327\end{array}$ & $\begin{array}{l}2303 \\
5500 \\
0\end{array}$ & $\begin{array}{l}\text { SKUR } \\
\text { U }\end{array}$ & $\begin{array}{l}186 \\
624\end{array}$ \\
\hline
\end{tabular}

callsign $=$ international radio call sign, up to seven characters, assigned to the vessel by its country of registry, imo = ship identification number that remains unchanged upon transfer of the ship's registration to another country, des $=$ destination, eta $=$ estimated time of arrival at destination.

Table 2: Example of dynamic vessel location information.

\begin{tabular}{|c|c|c|c|c|c|c|}
\hline $\begin{array}{l}\text { Time } \\
\text { stamp }\end{array}$ & $\mathrm{mmsi}$ & lon & lat & soc & $\operatorname{cog}$ & heading \\
\hline $\begin{array}{l}2018- \\
03-14 \\
23: 59\end{array}$ & $\begin{array}{c}2767760 \\
0\end{array}$ & $\begin{array}{l}21.4730 \\
23\end{array}$ & $\begin{array}{l}61.1262 \\
97\end{array}$ & 0.0 & 63.7 & 323 \\
\hline $\begin{array}{l}2018- \\
03-14 \\
23: 59\end{array}$ & $\begin{array}{c}2309922 \\
60\end{array}$ & $\begin{array}{l}21.4726 \\
92\end{array}$ & $\begin{array}{l}61.1272 \\
72\end{array}$ & 0.0 & 268.4 & 184 \\
\hline $\begin{array}{l}2018- \\
03-14 \\
23: 59\end{array}$ & $\begin{array}{c}2309926 \\
60\end{array}$ & $\begin{array}{l}28.8772 \\
23\end{array}$ & $\begin{array}{l}61.8771 \\
10\end{array}$ & 0.0 & 0.0 & 511 \\
\hline
\end{tabular}

$\mathrm{mmsi}=$ maritime mobile service identity, lon $=$ longitude, lat $=$ latitude, $\operatorname{sog}=$ speed over ground, $\operatorname{cog}=$ course over ground, to which direction the vessel is moving, heading $=$ to which direction does the head of the vessel point to.

Both the static and dynamic AIS information can also be explored from MarineTraffic.com website. For example, a snapshot of Baltic Madonna vessel is illustrated in Figure 1. 
Visualising maritime vessel open data for better situational awareness in ice conditions

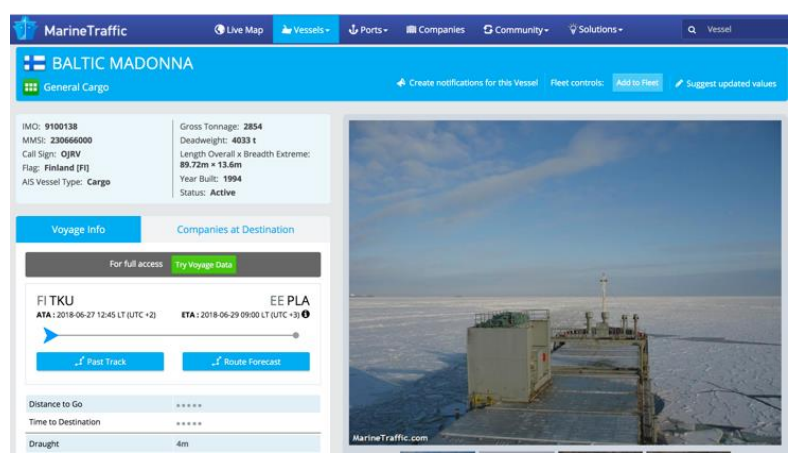

Figure 1. MarineTraffic.com information on Baltic Madonna.

In addition to AIS data, openly available weather data sources provide an important component to enhance the situational awareness of maritime vessels. For example, the Finnish Meteorological Institute provides data on ice conditions at Finnish sea areas. An example of available ice conditions data is illustrated in Figure 2. For a more detailed description of the available near-real-time ice condition data, see, e.g., $[14,15]$.

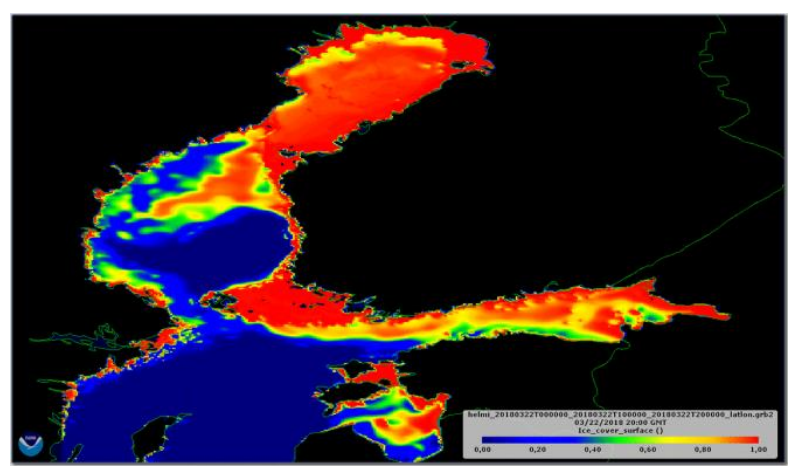

Figure 2. Ice conditions data from the Finnish Meteorological Institute visualized with National Centers for Environmental Information (NOAA) Weather and Climate Toolkit available at https://www.ncdc.noaa.gov/wet/.

\section{Previous computational studies on maritime vessels in ice conditions}

Computational studies on maritime vessels in ice conditions have been made from several perspectives. The most related previous studies include estimating the operability of ships in ridged ice fields [18], optimizing route in ice and the required amount of icebreaker assistance [31], route optimization in icecovered waters [17], and minimizing crossing time and the risk of ships getting stuck or damaged due to severe ice conditions [8]. An overview of the previous studies is illustrated in Table 3.
Mindtrek 2018, October 10-11, 2018, Tampere, Finland

The previous studies share some of the goals with this study. However, they do not provide the source code nor a detailed documentation of the methods that could be easily replicated. Furthermore, as the longer-term goal is to develop real-time or near-real-time applications that could, e.g., alarm a maritime vessel to reduce speed in a situation of predicted collision in ice conditions, there are limitations in the existing studies. For instance, in the study of Guinness et al. [8], the grid spacing in discretization of the sea area ranged from $20 \mathrm{~km}$ to $1 \mathrm{~km}$ between each grid point. When the grid sizes get smaller, the need for data warehousing $[26,27]$ that can handle big data streaming and heavy computation increases. In certain application areas, speed is the most critical aspect as the value of data, if not processed quickly, decreases with time. This is, for example, the case when trying to detect ship collisions in a window of opportunity [30] that allows preventative measures to be taken - the result of the analysis being considerably less valuable when the ships have already collided.

Table 3: Overview computational studies on maritime vessels in conditions

\begin{tabular}{|c|c|c|}
\hline & Problem & Results \\
\hline [18] & $\begin{array}{l}\text { Estimating the } \\
\text { operability of } \\
\text { ships in ice } \\
\text { conditions }\end{array}$ & $\begin{array}{l}\text { The obtained results } \\
\text { demonstrate that the proposed } \\
\text { model delivers reasonable } \\
\text { results in terms of ship speed } \\
\text { and the probability of getting } \\
\text { stuck in ice. }\end{array}$ \\
\hline [31] & $\begin{array}{l}\text { Optimum route in } \\
\text { ice and the } \\
\text { optimum amount } \\
\text { of icebreaker } \\
\text { assistance }\end{array}$ & $\begin{array}{l}\text { Described an approach intended } \\
\text { to provide multidisciplinary } \\
\text { integration by GIS and dynamic } \\
\text { simulation models based on } \\
\text { common object-oriented } \\
\text { program methodology. }\end{array}$ \\
\hline [17] & $\begin{array}{l}\text { Planning routes } \\
\text { that will reduce } \\
\text { fuel consumption, } \\
\text { travel time, and } \\
\text { the risk of getting } \\
\text { stuck in the ice }\end{array}$ & $\begin{array}{l}\text { The results show that the IRIS } \\
\text { system could, in principle, be } \\
\text { used in estimating ship transit } \\
\text { times, but also that there is still } \\
\text { a lot of work to do in improving } \\
\text { the different components of the } \\
\text { system. }\end{array}$ \\
\hline [8] & $\begin{array}{l}\text { Minimizing } \\
\text { crossing time and } \\
\text { the risk of ships } \\
\text { getting stuck or } \\
\text { damaged due to } \\
\text { severe ice } \\
\text { conditions }\end{array}$ & $\begin{array}{l}\text { A route optimization algorithm } \\
\text { 'A* algorithm', can be used to } \\
\text { minimize the costs associated } \\
\text { with sailing through ice- } \\
\text { covered waters. The effect of } \\
\text { icebreaker assistance can be } \\
\text { taken into account. }\end{array}$ \\
\hline
\end{tabular}

The problems addressed in previous computational studies (Table 3) are highly relevant. This study aims to introduce a data science solution that would enable building real-time or near-realtime applications for combatting the problems above and also for providing decision support to business operations relying on the transportation of goods on maritime vessels. 


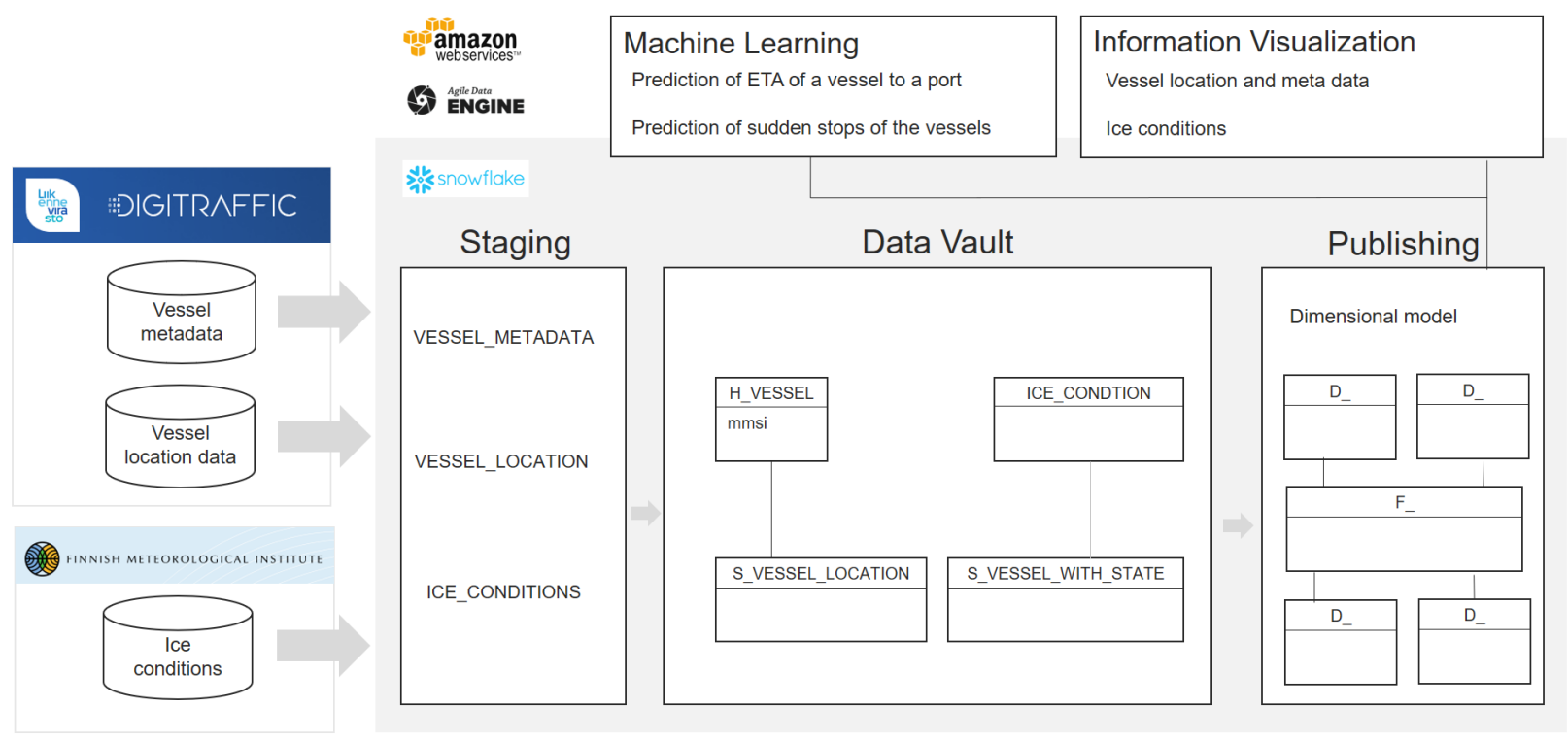

Figure 3. The proof of concept architecture of IceML. 4 Data science approach applied in the study

In an attempt to develop a data science approach that can provide real-time or near-real-time situational awareness of maritime vessels in ice conditions, a solution named IceML ('Ice Machine Learning') was developed. The ultimate goal of IceML is to apply machine learning [23] to winter navigation [33]. The proof of concept architecture is depicted in Figure 3.

As depicted in Figure 3, IceML retrieves vessel metadata and location data from Digitraffic's REST API (Digitraffic is a service operated by the Finnish Transport Agency offering real time traffic information covering road, rail, and maritime traffic) and ice conditions data from the Finnish Meteorological Institute. In staging, the data is copied as it is from source systems to the staging area [26]. The data warehousing solution is implemented to Amazon cloud (Amazon Web Services, AWS) running Snowflake [5] that offers virtually unlimited computing resources on demand as a pay-as-you-go service in the Amazon cloud. Data Vault [see 20] is used as modeling method for the data warehouse, as it allows flexibility of change and incremental development [26]. In publishing the data is transformed from data warehouse model to dimensional model [20], this fosters modularity as business rules (e.g. detection of ship collision) are executed after storing the actual data in data warehouse [26]. By doing so, the business intelligence team can work in parallel in implementation of data warehouse and publishing [27], i.e. information visualization and machine learning applications.

In order to demonstrate the IceML proof of concept, a use case of ship collision detection was implemented. By using AIS data and satellite images and ice condition data, it is possible to demonstrate the occurrence of maritime vessel collisions, which is the first step in building a warning system to avoid ship collisions. The same approach can be used also, for example, to estimate the time of arrival (ETA) of a vessel to a port. If the system could predict extra stops of a vessel within its journey to the destination port, the ETA could be better approximated. For instance, if the system could predict that there is an $80 \%$ chance that there will be a two hour extra stop in the ice, this information could be used in prediction of more accurate ETA.

Data visualization of the event was implemented in Python, available as open source from GitHub1. In addition to Python, the enriched open data is made available at the repository that can be easily visualized with third-party business intelligence applications, such as Tableau [24]. Next, visualizing a maritime vessel collision in ice conditions is presented using the data science approach described above.

\section{Visualising maritime vessel data and ice forecast data}

\section{Visualization of ice conditions and vessel movement}

Figure 4 and Figure 5 demonstrate 24 hours of AIS location data of a single vessel combined to ice forecast data. Figure 4 shows the path of the vessel through the changing ice conditions. The scale of the thickness of the ice is from 0 (bright color) to 1.4 meters (dark color). Figure 5 shows the same information as Figure 4 with speed over ground (sog) of the vessel.

\footnotetext{
1 Link to GitHub repository containing the source code: https://github.com/timole/iceml/
} 
Visualising maritime vessel open data for better situational awareness in ice conditions

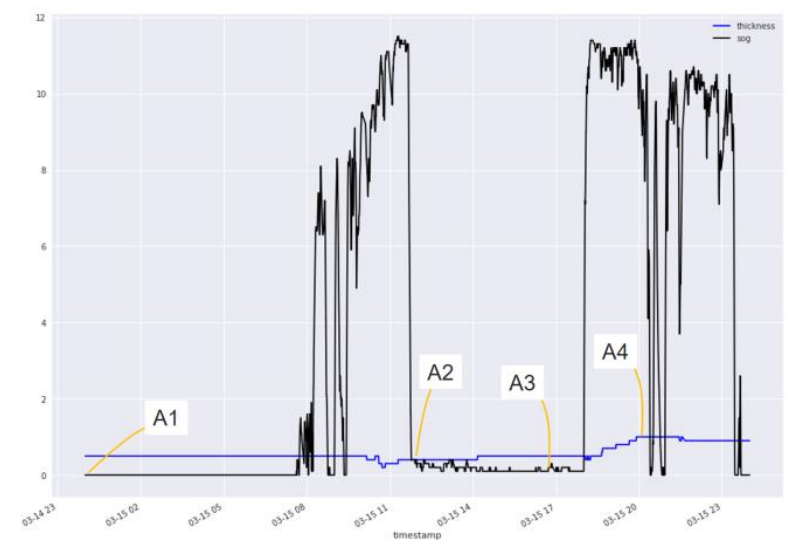

Figure 4. Ice conditions and vessel location data.

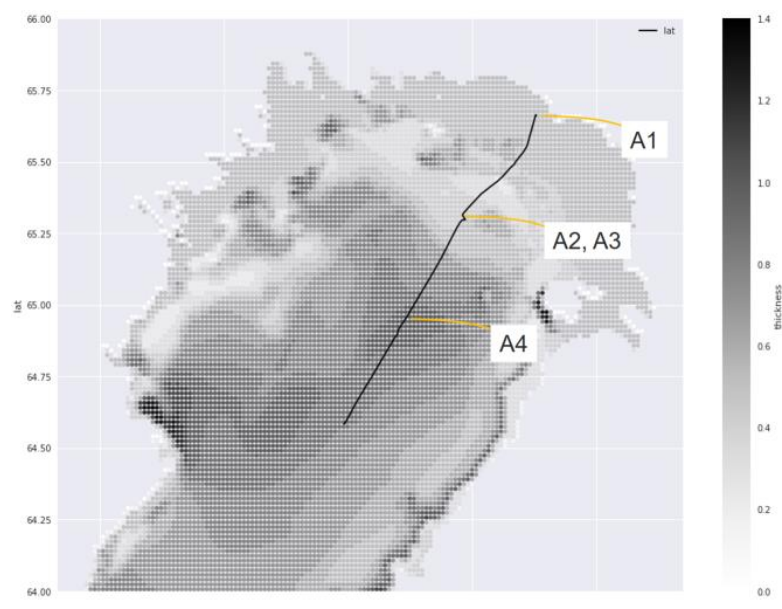

Figure 5. Vessel speed over ground (sog) and ice thickness.

First, the vessel is stopped in the port and the speed is 0 knot (one nautical mile per hour) in spot A1. In Figure 5 this spot is in the northern part of the map and in Figure 4 on the left of the timeline. Then, the speed is accelerated to over 10 knot. After that, the vessel stops and the speed falls down to 0 knot in spot A2. The stop in this case may be planned stop where the vessel waits for icebreaker assistance for several hours. In spot A3, there is a small movement visible on the map (Figure 5) and the vessel speed is also greater than zero (Figure 4). After a while, the vessel start moving again with speed of 10 knot. Then, the vessel gets stuck in to the ice two times more in spot A4.
Mindtrek 2018, October 10-11, 2018, Tampere, Finland

\section{Visualization of maritime vessel collision in ice}

One original intention of AIS data was to avoid the collisions of maritime vessels. Combining AIS data with satellite images and ice conditions data provides new opportunities to improve the collision detection of vessels. The following visualizations (Figure 6) illustrate a scenario of three ships colliding on a satellite map view as well as two- and three-dimensional timeline views of the vessel speeds.

In Figure 6, AIS data observations are plotted on top of a satellite image. The diagram depicts a journey of three vessels ending up to a collision. According to terminology used in [7], the event in this case is an escort with tow. The first vessel in the convoy is an icebreaker (Sisu) which tows a merchant vessel. The third vessel is another merchant vessel following the two other vessels in the convoy. Spots $\mathrm{A} 1, \mathrm{~B} 1$ and $\mathrm{C} 1$ point to the same AIS observation. In the diagram in the top left corner, spot A1 presents the speed of three vessels at 12:42, which is 10 knots. Spot B1 presents the same observation as $\mathrm{A} 1$ in a $3 \mathrm{D}$ visualization where the $\mathrm{x}$ and $\mathrm{y}$ axes depict the longitude and latitude and $\mathrm{z}$ axis depicts the speed of the vessel. Spot C1 points to the same observation as $\mathrm{A} 1$ and $\mathrm{B} 1$. The size of the circle depicts the speed. Then, spots $\mathrm{A} 2, \mathrm{~B} 2$ and $\mathrm{C} 2$ present the AIS observations of the three vessels at 12:49. Spot B2 is the moment of time when the icebreaker (Sisu) towing the vessel (Aura) suddenly stopped into the ice. It is noteworthy that the speed of the green vessel (BBC Virginia), stays steady for approximately one minute. Then, the collision occurs in spot A3 where the speed of the last vessel in convoy falls down to zero and the speed of the other two vessels is suddenly accelerated to $5 \mathrm{kn}$. The geolocation-based movement of the vessel in spots B3 and C3 stops.

\section{Visualizations of sudden stops of a vessel}

In the following diagrams, we present a visualization of vessels stopping suddenly into the ice. The goal is to recognize any patterns in the data.

Figure 7 presents the AIS location messages before sudden stop of the vessel (Aura). The exact time stamps of the AIS messages are presented with dots. It is noteworthy that there is a blackout in AIS data that lasts approximately five minutes before the sudden stop. The same pattern is visible in Figure 8 which presents the previous sudden stop of the same vessel (Aura).

There is a blackout in the AIS data for approximately 3.5 minutes before the vessel stops. The cause and source of the blackouts is currently unknown. The source of the blackout could be the open data API service or the AIS network itself, for instance. Future investigation is needed to find out if the blackout is related to the sudden stop of the vessels. 

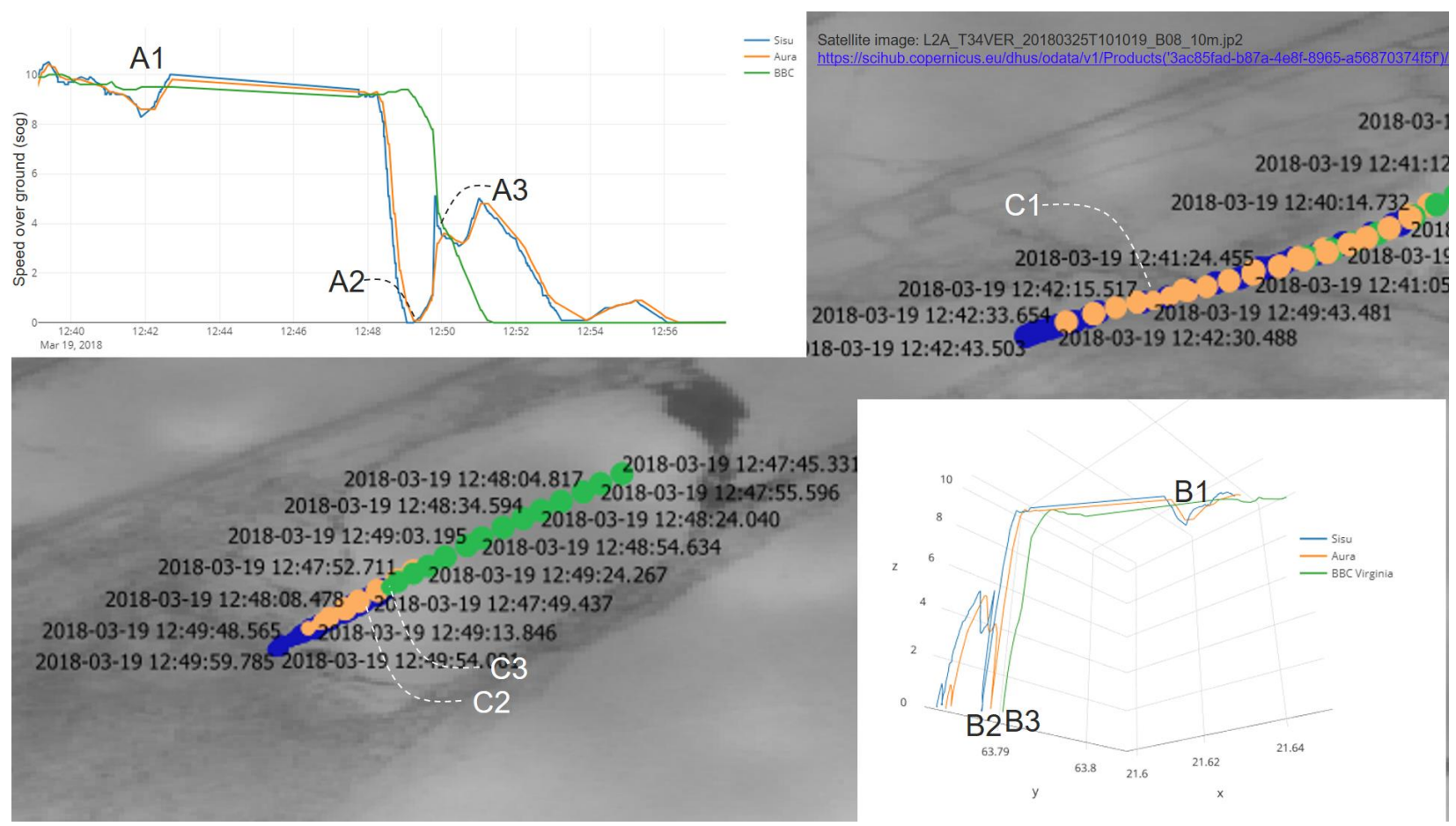

Figure 6. Visualization of AIS data on top of a satellite image.

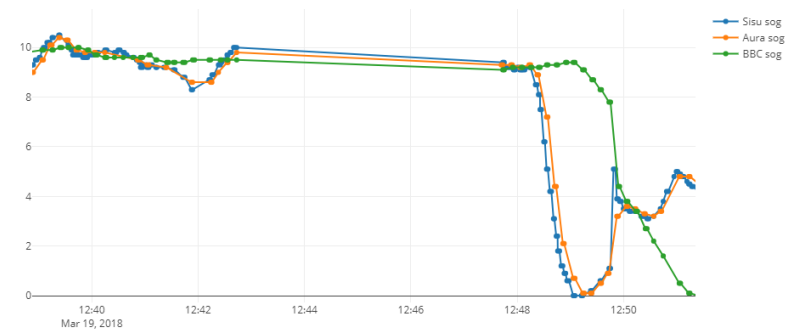

Figure 7. Visualization of a stopping vessel.

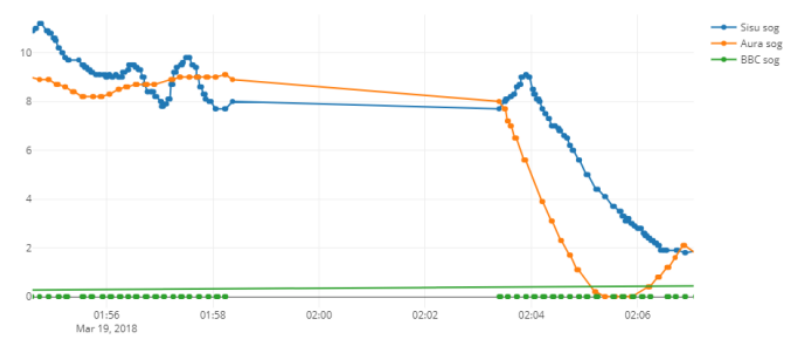

Figure 8. Visualization of previous stopping of the vessel.

\section{Discussion and conclusions}

We introduced a solution that can provide real-time or nearreal-time descriptive, diagnostic and predictive analytics for improving maritime vessel situational awareness in ice conditions. The idea of the solution is not to replace humans, but to provide decision aid ("support intelligence") for humans that have tacit knowledge and cognitive skills essential for safe operation of ships [see e.g. , 16]. The introduced solution is novel and follows a triple open science principle: open data, open source, and open access. The introduced IceML proof of concept demonstrates that by enriching and combining open data sources more valuable applications can be developed.

AIS data by itself provides several opportunities to improve maritime safety and to deliver information critical to business operations. However, not all the listed fields of AIS information are compulsory [29], and AIS data may also contain inaccurate information due to, for example, memory slips or omission to execute an action [10] or by intentional falsifications [21, 28]. A previous study on human factors related to AIS data found that some optional fields of AIS information, such as destination and ETA, are not considered important by the mariners as in most cases they are not updated [10]. The introduced data science approach could also be used to improve the quality of AIS data. For example, instead of relying on user inputted estimated time of arrival, a near-real-time prediction could be given and continuously updated based on objective AIS data, such as ship speed and location. 
As demonstrated, combining several open data sources provides new opportunities for more accurate, precise, and reliable predictions. Estimating the time of arrival of vessels in harbor in ice conditions using AIS data and ice condition data can lead to better situational awareness and enable, e.g., to take preventative measures in case a ship is predicted to arrive late to harbor or to get stuck in ice. Better situational awareness can lead to more optimal use of ice breakers or, e.g., for companies to take proactive business actions in the supply chain to mitigate the losses resulting from a ship arriving late.

By providing the results of the study as open source and enriched open data, other researchers can develop the solution further and address new problems not imagined in this study. Also, the previous studies applying discretization of sea areas by grid-based approaches to maritime vessels in ice conditions can benefit from this study by removing the data storage and computational limitations with the introduced approach. In addition, the outlined triple open science principle can make it easier for educational institutions or companies to adopt the approaches in either higher education or workplace learning.

\section{Future work}

The presented visualizations help to acquire more accurate insight on the data. They provide a basis for developing machine learning applications, for instance. The presented data sets thus provide a fruitful basis for developing more advanced solutions in the future. For instance, further investigating the patterns in the data related to sudden stops of the vessels, might enable prediction of them. Moreover, applying machine learning algorithms to the location and ice condition data could enable beneficial predictive analytics for winter navigation for both fullymanned and unmanned vessels.

\section{ACKNOWLEDGMENTS}

This work was supported by Gateway to Mercury Business funded by Business Finland.

\section{REFERENCES}

[1] Arbetter, T.E. Curry, J.A., Maslanik, J.A Arbetter, T.E., Curry, J.A. and Maslanik, J.A. 1999. Effects of Rheology and Ice Thickness Distribution in a Dynamic-Thermodynamic Sea Ice Model. Journal of Physical in a Dynamic-Thermodynamic Sea Ice Model. Journal of Physical
Oceanography. 29, $10 \quad$ (Oct. 1999), 2656-2670. DOI:https://doi.org/10.1175/15200485(1999)029<2656:EORAIT>2.0.CO;2.

[2] Bitz, C.M., Holland, M.M., Weaver, A.J. and Eby, M. 2001. Simulating the ice-thickness distribution in a coupled climate model. Journal of Geophysical Research: Oceans. 106, C2 (Feb. 2001), 2441-2463. DOI:https://doi.org/10.1029/1999JC000113.

[3] boyd, danah and Crawford, K. 2011. Six Provocations for Big Data. SSRN Electronic Journal. (Sep. 2011). DOI:https://doi.org/10.2139/ssrn.1926431

[4] Bruns, A. 2013. Faster than the speed of print: Reconciling 'big data' social media analysis and academic scholarship. First Monday. 18, 10 (Oct. 2013). DOI:https://doi.org/10.5210/fm.v18i10.4879.

[5] Dageville, B. et al. 2016. The Snowflake Elastic Data Warehouse. Proceedings of the 2016 International Conference on Management of
Data - SIGMOD '16 (New York, New York, USA, 2016), 215-226.

Ducruet, C. 2017. Advances in Shipping Data Analysis and Modeling: Tracking and Mapping Maritime Flows in the Age of Big Data. Routledge.

Goerlandt, F., Montewka, J., Zhang, W. and Kujala, P. 2017. An analysis of ship escort and convoy operations in ice conditions. Safety Science. 95 , (Jun. 2017), 198-209. DOI:https://doi.org/10.1016/J.SSCI.2016.01.004

Guinness, R., Saarimäki, J., Ruotsalainen, L., Kuusniemi, H., Goerlandt, J., Montewka, J., Berglund, R. and Kotovirta, V. 2014. A method for iceaware maritime route optimization. Position, Location and Navigation Symposium-PLANS 2014 (2014), 1371-1378.

Haapala, J., Lönnroth, N. and Stössel, A. 2005. A numerical study of open water formation in sea ice. Journal of Geophysical Research. 110 , C9 (2005), C09011. DOI:https://doi.org/10.1029/2003JC002200.

Harati-Mokhtari, A., Wall, A., Brooks, P. and Wang, J. 2007. Automatic Identification System (AIS): Data Reliability and Human Error Implications. Journal of Navigation. 60, 03 (Sep. 2007), 373 DOI:https://doi.org/10.1017/S0373463307004298.

Hibler, W.D. 1979. A Dynamic Thermodynamic Sea Ice Model. Journal of Physical Oceanography. 9, 4 (Jul. 1979), 815-846. DOI:https://doi.org/10.1175/1520-

0485(1979)009<0815:ADTSIM>2.0.CO;2.

Ilvonen, I., Jussila, J. and Kärkkäinen, H. 2015. Towards a businessdriven process model for knowledge security risk management: Making sense of knowledge risks. International Journal of Knowledge sense of knowledge risks. Internation
Management (IJKM). 11, 4 (2015), 1-18.

Jalonen, H. and Lönnqvist, A. 2009. Predictive business - fresh initiative or old wine in a new bottle. Management Decision 47, 10 (Nov, 2009), 1595-1609. DOI:https://doi.org/10.1108/00251740911004709.

Karvonen, J., Simila, M. and Heiler, I. Ice thickness estimation using SAR data and ice thickness history. IGARSS 2003, 2003 IEEE International Geoscience and Remote Sensing Symposium. Proceedings (IEEE Cat. No.03CH37477) 74-76.

Karvonen, J., Simila, M. and Lehtiranta, J. 2007. SAR-based estimation of the baltic sea ice motion. 2007 IEEE International Geoscience and Remote Sensing Symposium (2007), 2605-2608.

Kitada, M., Baldauf, M., Mannov, A., Svendsen, P.A., Baumler, R., Schröder-Hinrichs, J.-U., Dalaklis, D., Fonseca, T., Shi, X. and Lagdami, K. 2019. Command of Vessels in the Era of Digitalization. Advances in Human Factors, Business Management and Society. J. Kantola, S. Nazir, and T. Barath, eds. Springer. 339-350.

Kotovirta, V., Jalonen, R., Axell, L., Riska, K. and Berglund, R. 2009. A system for route optimization in ice-covered waters. Cold Regions Science and Technology. 55, 1 (Jan. 2009), 52-62. DOI:https://doi.org/10.1016/J.COLDREGIONS.2008.07.003.

Kuuliala, L., Kujala, P., Suominen, M. and Montewka, J. 2017. Estimating operability of ships in ridged ice fields. Cold Regions Science and Technology. 135, (2017), 51-61.

Kvamstad, B., Fjørtoft, K.E., Bekkadal, F., Marchenko, A. V. and Ervik, J.L. 2009. A Case Study from an Emergency Operation in the Arctic Seas. TransNav : International Journal on Marine Navigation and Safety of Sea Transportation. Vol. 3, nr 2 (2009).

Linstedt, D. and Olschimke, M. 2015. Building a scalable data warehouse with data vault 2.0. Morgan Kaufmann.

Mazzarella, F., Vespe, M. and Tarchi, D. 2016. AIS reception characterisation for AIS on/off anomaly detection. Information fusion (fusion) (2016), 1867-1873. 
Visualising maritime vessel open data for better situational awareness in ice conditions

[22] Mou, J.M., Tak, C. van der and Ligteringen, H. 2010. Study on collision avoidance in busy waterways by using AIS data. Ocean Engineering. 37, 5-6 (Apr. 2010$),$ DOI:https://doi.org/10.1016/J.OCEANENG.2010.01.012.

[23] Nasrabadi, N.M. 2007. Pattern Recognition and Machine Learning. Journal of Electronic Imaging. 16, 4 (Jan. 2007), 049901. DOI:https://doi.org/10.1117/1.2819119.

[24] Nita, S. and Mihailescu, M. 2017. IMPORTANCE OF BIG DATA IN MARITIME TRANSPORT. Scientific Bulletin "Mircea cel Batran" Naval Academy. 20, 1 (2017).

[25] Porter, M.E. and Heppelmann, J.E. 2015. How smart, connected products are transforming companies. Harvard Business Review. 93, 10 (2015), 96-114.

[26] Puonti, M., Järvi, J. and Mikkonen, T. 2018. A Continuous Delivery Framework for Business Intelligence. Information Modelling and Knowledge Bases XXIX. IOS Press. 248-262.

[27] Puonti, M., Lehtonen, T., Luoto, A., Aaltonen, T. and Aho, T. 2016. Towards Agile Enterprise Data Warehousing. The Eleventh International Conference on Software Engineering Advances (Rome, 2016).

[28] Ray, C., Iphar, C. and Napoli, A. 2016. Methodology for Real-Time Detection of AIS Falsification. Maritime Knowledge Discovery and Anomaly Detection Workshop (2016), 74-77.

[29] Ristic, B., Scala, B., Morelande, M. and Gordon, N. 2008. Statistical analysis of motion patterns in AIS data: Anomaly detection and motion prediction. Fusion 2008: Proceedings of the 11th International Conference on Information Fusion. (Cologne, 2008).

[30] Sull, D. and Wang, Y. 2005. Made In China: What Western Managers Can Learn from Trailblazing Chinese entrepreneurs. Harvard Business Press.

[31] Tarovik, O. V., Topaj, A., Bakharev, A.A., Kosorotov, A. V., Krestyantsev, A.B. and Kondratenko, A.A. 2017. Multidisciplinary Approach to Design and Analysis of Arctic Marine Transport Systems. Volume 8: Polar and Arctic Sciences and Technology; Petroleum Technology (Jun. 2017), V008T07A005.

[32] Tetreault, B.J. Use of the Automatic Identification System (AIS) for Maritime Domain Awareness (MDA). Proceedings of OCEANS 2005 MTS/IEEE $1-5$

[33] Valdez Banda, O.A., Goerlandt, F., Montewka, J. and Kujala, P. 2015. A risk analysis of winter navigation in Finnish sea areas. Accident Analysis \& Prevention. 79, (Jun. 2015), 100-116. DOI:https://doi.org/10.1016/J.AAP.2015.03.024.

[34] Vassakis, K., Petrakis, E. and Kopanakis, I. 2018. Big Data Analytics: Applications, Prospects and Challenges. Springer, Cham. 3-20.

[35] Weintrit, A. 2009. Marine navigation and safety of sea transportation. CRC.

[36] Zaman, I., Pazouki, K., Norman, R., Younessi, S. and Coleman, S. 2017. Challenges and Opportunities of Big Data Analytics for Upcoming Regulations and Future Transformation of the Shipping Industry. Procedia engineering. 194, (2017), 537-544.

[37] Zanin, M., Papo, D., Sousa, P.A., Menasalvas, E., Nicchi, A., Kubik, E. and Boccaletti, S. 2016. Combining complex networks and data mining: Why and how. Physics Reports. 635, (May 2016), 1-44. DOI:https://doi.org/10.1016/J.PHYSREP.2016.04.005. 